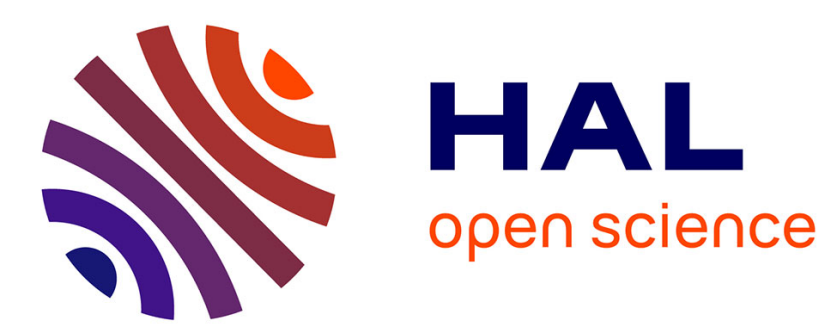

\title{
A scaling analysis of ozone photochemistry: II Investigation of the similarity relationship
}

B. Ainslie, D. G. Steyn

\section{To cite this version:}

B. Ainslie, D. G. Steyn. A scaling analysis of ozone photochemistry: II Investigation of the similarity relationship. Atmospheric Chemistry and Physics Discussions, 2005, 5 (6), pp.12985-13010. hal00302011

\section{HAL Id: hal-00302011 \\ https://hal.science/hal-00302011}

Submitted on 19 Dec 2005

HAL is a multi-disciplinary open access archive for the deposit and dissemination of scientific research documents, whether they are published or not. The documents may come from teaching and research institutions in France or abroad, or from public or private research centers.
L'archive ouverte pluridisciplinaire HAL, est destinée au dépôt et à la diffusion de documents scientifiques de niveau recherche, publiés ou non, émanant des établissements d'enseignement et de recherche français ou étrangers, des laboratoires publics ou privés. 
Scaling ozone photochemistry II

B. Ainslie and D. G. Steyn

\section{A scaling analysis of ozone photochemistry: II Investigation of the similarity relationship}

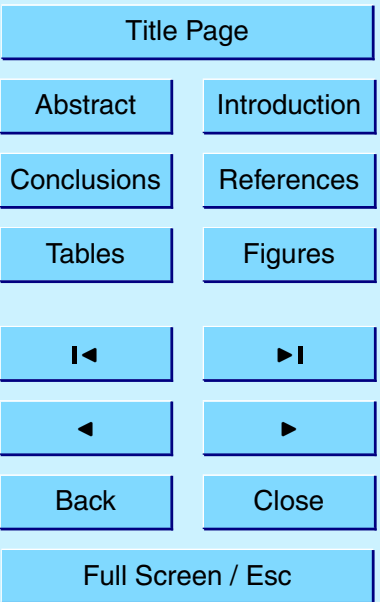

(C) 2005 Author(s). This work is licensed under a Creative Commons License.

Print Version

Interactive Discussion

EGU 


\section{Abstract}

The similarity relationship for maximum ozone concentration as a function of initial precursor concentrations developed in the first article of this 2-part series exhibits a scale break, most easily seen after a Weibull transformation, which identifies a characteristic

scale for ozone photochemistry. In this paper, we investigate the similarity relationship using simple semi-quantitative models and model output. From this investigation, we develop a set of properties characterizing ozone-precursor relationships. We find the scaling break is associated with a change in the temporal variability of ozone production. Finally, we examine a series of smog chamber experiments for evidence of a It is difficult to tell if the lack of distinct break is due to smog chamber experimental limitations, a bias in the test conditions or if the processes leading to the scaling break are overly enhanced by chemical mechanisms.

\section{Introduction}

15 Ozone isopleth diagrams are a useful tool for summarizing the dependence of ozone formation on initial precursor concentrations. The most striking feature of these diagrams is the non-linear relationship between ozone and its precursors - creating a response surface with distinct $\mathrm{VOC}$ - and $\mathrm{NO}_{\mathrm{x}}$-sensitive regions. These regions can be characterized in several (related) ways: in terms of response of maximum ozone concentration to changing initial $\mathrm{NO}_{\mathrm{x}}$ concentration at fixed VOC concentration (National Research Council, 1991); in terms of the relative importance of peroxides to nitric acid production (Sillman, 1995); in terms of the fraction of radicals lost in reactions involving $\mathrm{NO}_{x}$ (Kleinman, 2005); by the fraction of $\mathrm{HO}_{2}^{*}$ radicals that react with $\mathrm{NO}$ (Tonnesen and Dennis, 2000); by the extent to which $\mathrm{NO}_{x}$ has reacted to produce the maximum possible ozone concentration (Blanchard et al., 1999) or by the ratio of the lifetime of $\mathrm{OH}^{\bullet}$ with respect to losses by reactions with VOC and $\mathrm{NO}_{\mathrm{x}}$ (Kirchner et al., 2001).
ACPD

$5,12985-13010,2005$

Scaling ozone photochemistry II

B. Ainslie and D. G. Steyn

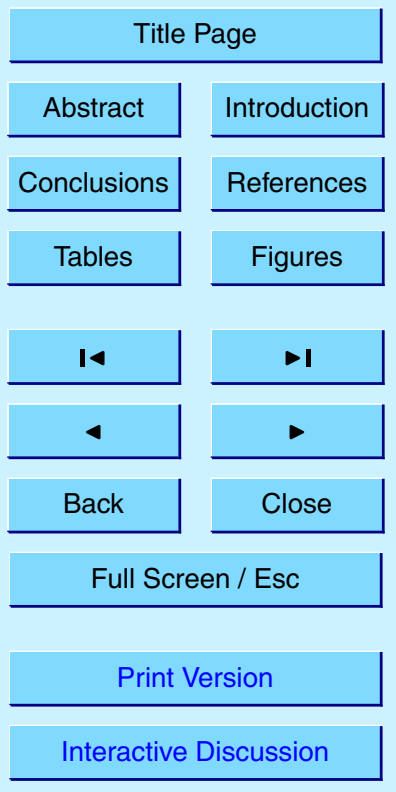

EGU 
The dimensional analysis of Ainslie and Steyn (2005) suggests these regions can also be characterized by the change in behaviour of the ratio of dimensionless maximum ozone concentration to dimensionless initial $\mathrm{NO}_{\mathrm{x}}$ concentration:

$$
\frac{\left[\mathrm{O}_{3}\right]_{\max }}{j_{a v} / k_{\mathrm{NO}}} /\left(\frac{\left[\mathrm{NO}_{\mathrm{x}}\right]_{\mathrm{O}}}{j_{a v} / k_{\mathrm{NO}}}\right)^{a}
$$

5 across a specific value $(\beta)$ of the ratio of initial VOC to $\mathrm{NO}_{\mathrm{x}}$ concentrations $(R)$. In this paper, we use this behaviour to guide the development of semi-quantitative models for ozone formation. From these models, we infer a set of properties which characterize simple ozone-precursor relationships. In many ways, our line of inquiry parallels the development of the Integrated Empirical Rate (IER) model (Johnson, 1984) except this model was based on smog chamber data whereas we use model output. As such, our results express the behaviour of a set of mathematical relations describing ozone photochemistry - an imperfect representation of the actual atmosphere - which may differ from the (also imperfect) representation of the atmosphere given by smog chambers. As a result, we also examine how well the properties developed in this paper can be used to characterize ozone formation in a smog chamber.

\section{A step-function model for ozone production}

Ozone concentrations are the product of the integrated rate of chemical production in excess of chemical destruction over the history of a precursor mixture. As such, the net chemical production, $P\left(\mathrm{O}_{3}\right)$, provides a fundamental framework for studying ozoneprecursor relationships. Our analysis begins with a simple model for ozone production which is a function of initial precursor concentrations and the integrated $\mathrm{NO}_{2}$ photolysis rate constant $\left(j_{\mathrm{NO} 2}\right)$ :

$j(t)=\int_{\text {to }}^{t} j_{\mathrm{NO} 2} d s$.

\section{ACPD}

5, 12985-13010, 2005

\section{Scaling ozone photochemistry II}

B. Ainslie and D. G. Steyn

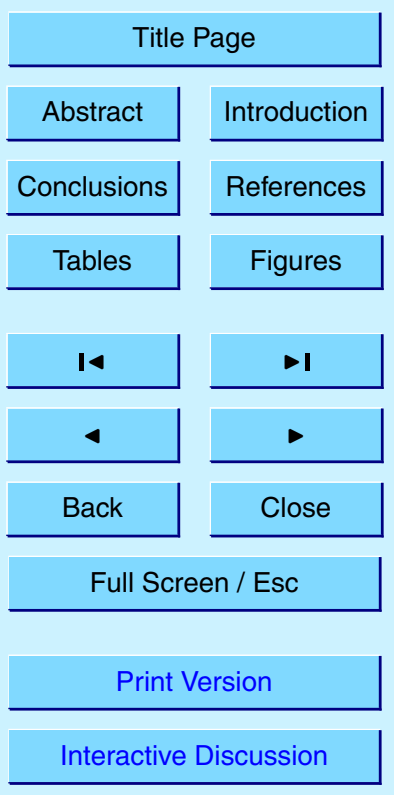

EGU 
We follow Johnson (1984) by using $j(t)$ as a proxy for cumulative actinic flux and consider it a dimensionless process time. We define $P_{j}\left(\mathrm{O}_{3}\right)$ as the sensitivity of ozone concentration to the integrated $\mathrm{NO}_{2}$ photolysis rate constant:

$P_{j}\left(\mathrm{O}_{3}\right) \equiv \frac{d\left[\mathrm{O}_{3}\right]}{d j(t)}$

5 We now develop a semi-quantitative model for $P_{j}\left(\mathrm{O}_{3}\right)$ in order to provide a qualitative description of ozone formation. This model is not intended to capture specifics of photochemical process, rather it is a toy model used to illustrate general principles. Specifically, we relate individual properties of the semi-quantitative model with basic features of the similarity function such as the scaling break and the "s-shaped" profile.

\section{Sects. 3 and 4 as the analysis reveals model limitations.}

We begin with a step-function model for $P_{j}\left(\mathrm{O}_{3}\right)$ where production is initially constant before switching to a zero-production regime at some time $j^{*}$. We give $P_{j}\left(\mathrm{O}_{3}\right)$ a VOC dependence by assuming the constant production increases with increasing initial VOC concentration (for now we ignore any $\mathrm{NO}_{x}$ dependence but include these in Sect. 4). We define the model with the following four rules which we illustrate in Fig. 1:

Rule I: $P_{j}\left(\mathrm{O}_{3}\right)$ is initially constant until a critical j-value $\left(j^{*}\right)$ at which production drops to zero. We motivate this rule by noting that most precursor mixtures are initially radical limited, regardless of VOC to $\mathrm{NO}_{x}$ ratio, with production limited by the rate of $\mathrm{OH}^{\bullet}$ attack on VOC, however, as the system reacts and $\mathrm{NO}_{\mathrm{x}}$ is converted to $\mathrm{NOz}$, the system stops reacting and production ceases.

Rule II: The larger the initial VOC concentration, the larger initial $P_{j}\left(\mathrm{O}_{3}\right)$. Again, we assume production is limited by rate of $\mathrm{OH}^{\bullet}$ attack on VOC and so scales with [VOC] $]_{0}$. Rule III: The larger the initial VOC concentration, the earlier production ceases. With increased production, we expect ozone formation to occur sooner accompanied by more rapid $\mathrm{NO}_{z}$ production and the earlier onset of $\mathrm{NO}_{x}$-limited conditions.

Rule IV: The switchover time $\left(j(t)^{*}\right)$ is such that the area under the $P_{j}\left(\mathrm{O}_{3}\right)$-j curve is independent of initial VOC concentration. We associate the shift in production with 12988

ACPD

$5,12985-13010,2005$

Scaling ozone photochemistry II

B. Ainslie and D. G. Steyn

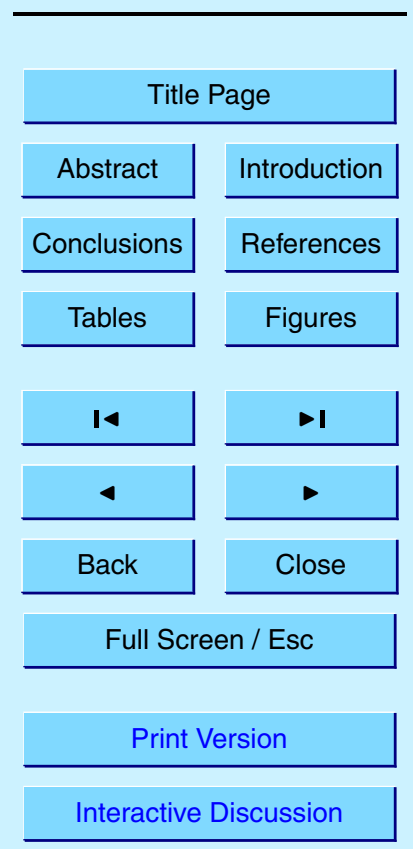

EGU 
a switch to $\mathrm{NO}_{\mathrm{x}}$-limited conditions where we have found maximum ozone concentrations (corresponding to the total area under the $P_{j}\left(\mathrm{O}_{3}\right)-j(t)$ curve) to be independent of $[\mathrm{VOC}]_{\mathrm{O}}$ (Ainslie and Steyn, 2005).

In Fig. 2 we consider the relationship between ozone production, ozone concentra5 tion and maximum ozone concentration, using the step-function model, for a set of precursor mixtures having fixed $\left[\mathrm{NO}_{\mathrm{x}}\right]_{0}$, a range of $[\mathrm{VOC}]_{0}$ and total actinic flux set at $j\left(t_{\text {end }}\right)=300$. The production curves (Fig. 2A) give rise to ozone concentration curves which increase linearly (Fig. $2 \mathrm{C}$ ) and if initial production is great enough and switchover occurs, then ozone concentrations reach a maximum and remain constant. For exam10 ple, while the highest production curve $\left([\mathrm{VOC}]_{0}=4.0 \mathrm{ppm}\right)$ results in ozone concentrations rising quickest, the $[\mathrm{VOC}]_{0}=3.0$ and $[\mathrm{VOC}]_{0}=2.0 \mathrm{ppm}$ curves also achieve the same final ozone concentration. The low VOC curve $\left([\mathrm{VOC}]_{0}=1.0\right)$ rises the slowest and does not reach the maximum before simulation end.

In Fig. 2D, we plot $\left[\mathrm{O}_{3}\right]_{\max }$ concentration as a function of $[\mathrm{VOC}]_{0}$, where two linear line 15 segments have been fitted to the results. The arrow running between Figs. $2 \mathrm{C}$ and $2 \mathrm{D}$ shows how the final ozone concentration along any curve in Fig. $2 \mathrm{C}$ becomes the maximum concentration for that [VOC] $]_{0}$ and is therefore used as the ozone concentration in the $\left[\mathrm{O}_{3}\right]_{\max }$ versus [VOC] olot (to avoid clutter, only four curves are shown in Figs. $2 \mathrm{~A}$ and $\mathrm{C}$, whereas Fig. $2 \mathrm{D}$ has been plotted using an additional eight [ $\left.\mathrm{VOC}]_{0}\right)$. Figure 2D piecewise linear and attains its maximum value - unlike the "s-shaped" curves found in non-diluted model output (Fig. 1 of Ainslie and Steyn, 2005) ${ }^{1}$. We check for the pres-

\footnotetext{
${ }^{1}$ While the similarity relationship in Ainslie and Steyn (2005) results from a plot of $\left[\mathrm{O}_{3}\right]_{\max } /\left[\mathrm{NO}_{\mathrm{x}}\right]_{0}{ }^{a}$ (or more precisely dimensionless $\left[\mathrm{O}_{3}\right]_{\max }$ and dimensionless $\left[\mathrm{NO}_{\mathrm{x}}\right]_{0}$ ) versus $R$, it can be interpreted as a series of cross-sectional cuts from an isopleth diagram each along a different line of constant $\left[\mathrm{NO}_{\mathrm{x}}\right]_{0}$. Scaling $\left[\mathrm{O}_{3}\right]_{\max }$ by the underlying $\left[\mathrm{NO}_{\mathrm{x}}\right]_{0}$ vertically compresses each cross-section to a common maximum. Furthermore, plotting against $R$ (and not $[\mathrm{VOC}]_{0}$ ) shifts each cross-section horizontally until they overlap. As a result, a single $\left[\mathrm{O}_{3}\right]_{\max }$ versus $[\mathrm{VOC}]_{0}$ (at a fixed $\left[\mathrm{NO}_{\mathrm{x}}\right]_{0}$ ) plot produces a curve analogous to the similarity relationship;
}

ACPD

5, 12985-13010, 2005

\section{Scaling ozone photochemistry II}

B. Ainslie and D. G. Steyn

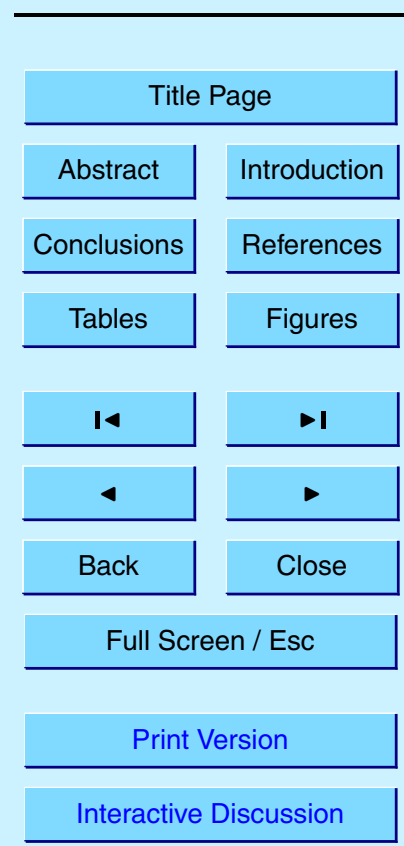

EGU 
ence of a scaling break by Weibull transforming the maximum ozone concentrations and plotting against $\ln [\mathrm{VOC}]_{\mathrm{o}}$ (Fig. 2B). To avoid singularities when Weibull transforming a value of unity, we choose the normalizing constant to be $1 \%$ larger than the maximum ozone concentration; a choice which does not affect our conclusions. The

5 Weibull transformed data cluster onto two curves with the one corresponding to maximum ozone concentrations under $\mathrm{NO}_{\mathrm{x}}$-limited conditions being a straight line with zero slope. This zero slope and the linear dependence of $\left[\mathrm{O}_{3}\right]_{\max }$ on $[\mathrm{VOC}]_{0}$ highlight two discrepancies between the step-function model and the similarity functions given in Ainslie and Steyn (2005). Both are related to the simplistic way the dependence of $10 \quad[\mathrm{VOC}]_{0}$ and $j(t)$ on $P_{j}\left(\mathrm{O}_{3}\right)$ have been parameterized in the step-function model. Despite these discrepancies, it should be noted that the step function model forms the basis of the IER model (Johnson, 1984), a simple set of formulae used to quantitatively describe ozone formation, developed from the analysis of an extensive set of outdoor smog chamber experiments. As a result, Fig. $2 \mathrm{C}$ duplicates the IER model (but with $\mathrm{O}_{3}$ plotted against $j(t)$ instead of primary smog products $(P S P)$ ). While this model has been criticized for its linear dependence of maximum ozone concentration on initial $\mathrm{NO}_{\mathrm{x}}$ (Blanchard, 2000), the basis for the model is supported by environmental chamber data and current understanding of atmospheric chemistry (Blanchard et al., 1994). As such, we find the step function model provides a useful framework for our analysis and modify it in Sect. 3 to include a more realistic temporal variability for $P_{j}\left(\mathrm{O}_{3}\right)$.

\section{A more complex model for ozone production}

The step-function's linear $\left[\mathrm{O}_{3}\right]_{\max }-[\mathrm{VOC}]_{0}$ relationship gives rise to "L" shaped isopleths (not shown) which suggests the parameterization does not capture the strong inhibition of ozone formation above the ridgeline exhibited by most chemical mechanisms
ACPD

5, 12985-13010, 2005

Scaling ozone photochemistry II

B. Ainslie and D. G. Steyn

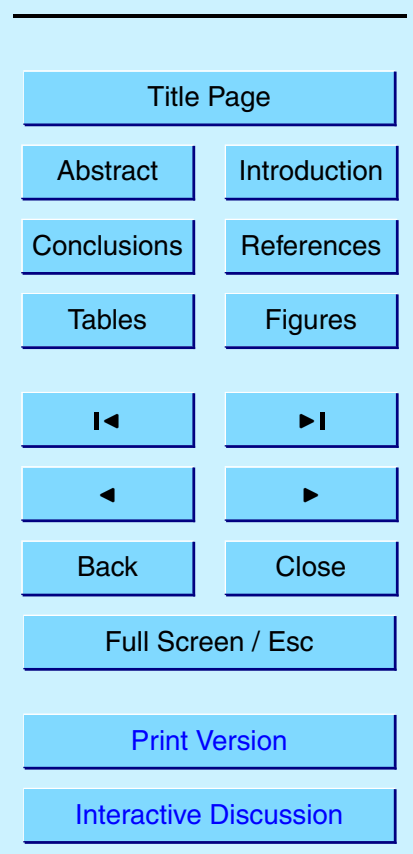

EGU tions involving a competition between $\mathrm{NO}_{2}$ and VOCs for available radicals with ozone independent of any underlying parameterization. 
photolysis representing a major inorganic source for these radicals. To parameterize this behaviour, we let $P_{j}\left(\mathrm{O}_{3}\right)$ mirror the temporal evolution for the ozone photolysis rate: production starts at zero, increases, reaches a maximum value and then decreases. In addition, to ensure the corresponding ozone concentrations asymptotically approach 5 their maximum value, we make the decrease exponential. Finally, we make the maximum value of $P_{j}\left(\mathrm{O}_{3}\right)$ increase with [VOC] $]_{0}$ and the j-value at this maximum decrease with [VOC]. We illustrate this ozone production model in Fig. 3.

This model is easily parameterized using a Weibull distribution with scale factor inversely proportional to $[\mathrm{VOC}]_{0}$. For such a parameterization, both the corresponding $10 \quad\left[\mathrm{O}_{3}\right]$ versus $j(t)$ curves and the $\left[\mathrm{O}_{3}\right]_{\max }$ versus $[\mathrm{VOC}]_{0}$ curve, would be parameterized by Weibull functions and produce "s-shaped" curves. However, it is evident that such a parameterization model would not produce a scaling break upon Weibull transformation (the single Weibull function parameterization produces a single straight line upon transformation) ${ }^{2}$. This suggests that in order to produce a realistic parameterization for ozone production which includes a scaling break, it is not sufficient for the parameterization to include: a local maximum in production, a change in curvature or even exponentially decaying production. For the step-function model, the break arises from the abrupt change in the functional form of $P_{j}\left(\mathrm{O}_{3}\right)$, reflecting a structural change in behaviour of the chemical mechanism, occurring between high and low $\mathrm{NO}_{\mathrm{x}}$ regimes. As Kleinman (1994) suggests, this change represents more than continuous differences in production as $\mathrm{NO}_{\mathrm{x}}$ is varied. We conclude that in order to produce a scaling break, our semi-quantitative model should have an abrupt change in functional form for $P_{j}\left(\mathrm{O}_{3}\right)$. To further characterize this change in functional form, we consider the influence of $\mathrm{NO}_{\mathrm{x}}$ on $P_{j}\left(\mathrm{O}_{3}\right)$. In so doing, we generalize the four rules used to develop the toy model in 25 Sect. 2 and define a set of properties characterizing ozone-precursor relationships.

\footnotetext{
${ }^{2}$ The same conclusions hold even if $P_{j}\left(\mathrm{O}_{3}\right)$ is parameterized by a lognormal or gamma function. In these cases, the Weibull transformed data is slightly curved but, again, does not produce a distinct break.
}

ACPD

$5,12985-13010,2005$

\section{Scaling ozone photochemistry II}

B. Ainslie and D. G. Steyn

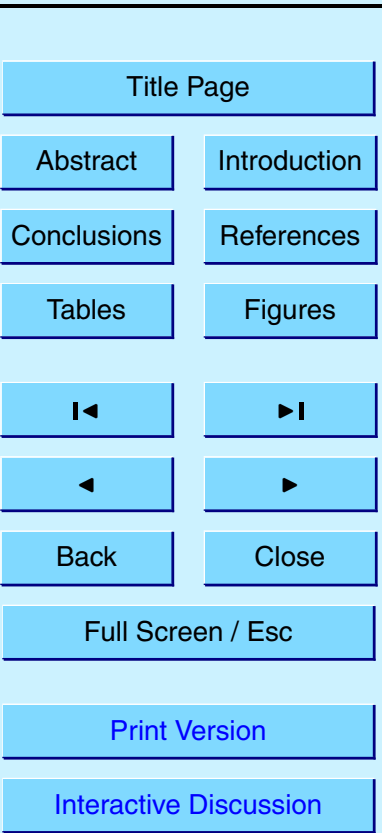

EGU 


\section{General properties for ozone-precursor relationships}

In order to characterize ozone production with realistic $\mathrm{NO}_{\mathrm{x}}$ dependence, we examine the temporal variability of ozone concentration from a set of nine simulations using the OZIPR trajectory model with an urban speciation based on Stockwell et al. (1997).

5 Each simulation begins with an initially well mixed charge of $\mathrm{VOC}$ and $\mathrm{NO}_{\mathrm{x}}$, and in order to study the chemical processes in isolation from competing physical processes, we allow no subsequent emissions, dilution or deposition. A fixed temperature of $25^{\circ} \mathrm{C}$ is used throughout the 11-h simulation with an actinic flux appropriate to Vancouver B.C. (latitude $49.1^{\circ} \mathrm{N}$ ) on 21 June. To make presentation of results more concise and guided by our analysis of the dependence of dimensionless maximum ozone concentration on dimensionless actinic flux (Ainslie and Steyn, 2005), we plot $\left[\mathrm{O}_{3}\right](\mathrm{t})$ versus $R \times j(t)^{c}$ (with $c=1.2$ ) in Fig. 4. This figure shows three plots, each giving results from three simulations having different $[\mathrm{VOC}]_{0}$ but common $\left[\mathrm{NO}_{\mathrm{x}}\right]_{0}$, with corresponding $R$ values of: 12,24 and 30 (all greater than $\beta(=9.4)$, the $[\mathrm{VOC}]_{0} /\left[\mathrm{NO}_{\mathrm{x}}\right]_{0}$ ratio at the 15 scaling break). In Fig. $4 \mathrm{~A}$ each simulation starts with an initial $\mathrm{NO}_{\mathrm{x}}$ concentration of $15 \mathrm{ppb}$, while in Fig. 4B it is $45 \mathrm{ppb}$ and $75 \mathrm{ppb}$ in Fig. $4 \mathrm{C}$. From these plots, we make the following observations:

- The rate of increase in $\left[\mathrm{O}_{3}\right]$ slows down at $R \times j^{c} \approx 8600$; independent of both initial $\left[\mathrm{NO}_{\mathrm{x}}\right]_{0}$ and $[\mathrm{VOC}]_{0}$. We associate the slowing with a switch in the behaviour of ozone production and observe the timing of this switch depends on $R$ - occurring sooner for mixtures having higher $R$-values.

- Ozone concentrations at the time of the switch are roughly the same for simulations with identical $\left[\mathrm{NO}_{\mathrm{x}}\right]_{0}$; independent of $[\mathrm{VOC}]_{0}$. In terms of production, this implies that for a given initial $\left[\mathrm{NO}_{x}\right]_{0}$, switchover occurs for a fixed area under

\section{Scaling ozone photochemistry II}

B. Ainslie and D. G. Steyn

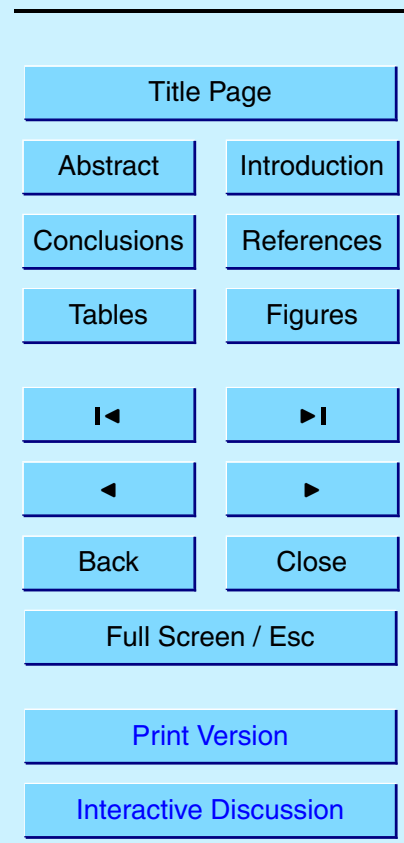

EGU constant $\left[\mathrm{O}_{3}\right]$ at switchover and with the switchover occurring sooner for higher $R$ values, peak $P_{j}\left(\mathrm{O}_{3}\right)$ increases with $R$. Finally, ozone concentrations at the switch 
increase with increasing $\left[\mathrm{NO}_{\mathrm{x}}\right]_{0}$ for simulations with constant $R$-values.

- For simulations with identical $R$-values, increasing $\left[\mathrm{NO}_{\mathrm{x}}\right]_{0}$ causes $\left[\mathrm{O}_{3}\right]$ to initially increases more rapidly (implying peak $P_{j}\left(\mathrm{O}_{3}\right)$ increases with $\left.\left[\mathrm{NO}_{\mathrm{x}}\right]_{0}\right)$ and ultimately reach a higher final value.

5 In an effort to understand the scaling break, we developed a toy model for $P_{j}\left(\mathrm{O}_{3}\right)$ based on four rules. While the Weibull transformed $\left[\mathrm{O}_{3}\right]_{\max }$ vs $[\mathrm{VOC}]_{0}$ plot (Fig. $2 \mathrm{C}$ ) based on this toy model produced a scaling break, the line segment after the break had zero slope - a characteristic not observed in similar plots using model output (Ainslie and Steyn, 2005). In an effort to remedy this and other discrepancies, a 10 more complex model was considered which produced an "s-shaped" profile for the similarity relationship but at the expense of eliminating the scaling break. From this we concluded a semi-quantitative model producing a scaling break required a change in function form for the parameterization of $P_{j}\left(\mathrm{O}_{3}\right)$. To generalize our results and include a $\mathrm{NO}_{\mathrm{x}}$-dependence into our analysis, we have examined model output. From this 15 output, it appears that any parameterization of ozone formation should include the following properties:

Property I: To ensure the temporal variability of $\left[\mathrm{O}_{3}\right]$ is "s-shaped", $P_{j}\left(\mathrm{O}_{3}\right)$ should initially increase, reach a peak value and then asymptotically decrease.

Property II: $P_{j}\left(\mathrm{O}_{3}\right)$ should increase with $R$ and with $\left[\mathrm{NO}_{\mathrm{x}}\right]_{0}$.

20 Property III: To ensure the corresponding Weibull transformed similarity relationship has a scaling break, the parameterization of $P_{j}\left(\mathrm{O}_{3}\right)$ should have a change in function form.

Property IV: Larger $R$-values should cause the transition time $\left(j^{*}\right)$ of $P_{j}\left(\mathrm{O}_{3}\right)$ to occur sooner.

25 Property V: The total area under the $P_{j}\left(\mathrm{O}_{3}\right)-j(t)$ curve, as well as the area up to the transition time should be functions of $\left[\mathrm{NO}_{\mathrm{x}}\right]_{0}$ only.

Property VI: The corresponding parameterization for $\left[\mathrm{O}_{3}\right]$ should scale with $R \times j(t)^{C}$.
ACPD

5, 12985-13010, 2005

Scaling ozone photochemistry II

B. Ainslie and D. G. Steyn

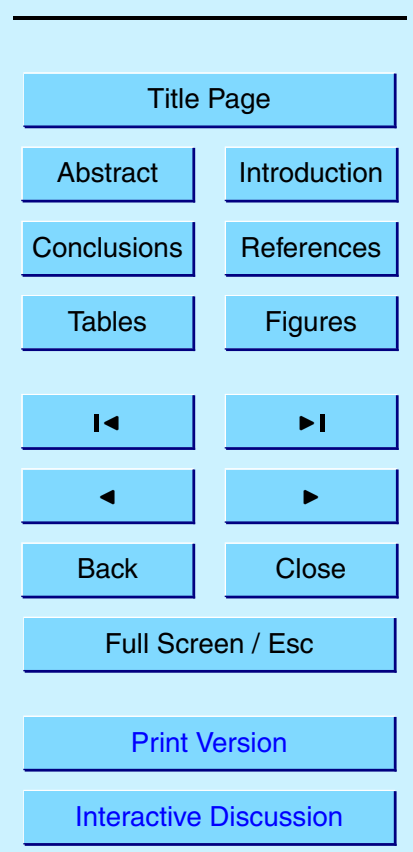

EGU 
It is easy to show properties II-VI generalize the IER model (see Appendix) and based on the scaling analysis of Ainslie and Steyn (2005), and work by Blanchard (2000) and Chang and Rudy (1993), we suggest one additional property:

Property VII: The corresponding relationship between $\left[\mathrm{O}_{3}\right]_{\max }$ and $\left[\mathrm{NO}_{\mathrm{x}}\right]_{0}$, for large 5 VOC to $\mathrm{NO}_{\mathrm{x}}$ ratios, should show $\left[\mathrm{O}_{3}\right]_{\max } \propto\left[\mathrm{NO}_{\mathrm{x}}\right]_{0}{ }^{a}$ with $\mathrm{a}<1$.

In Ainslie and Steyn (2005), dimensional analysis was used to represent the integrated behaviour of a photochemical mechanism. In this paper, the results of the dimensional analysis have guided the development of a semi-quantitative model for 10 ozone production and help produce a set of properties which characterize ozoneprecursor relationships. We find a parameterization of $P_{j}\left(\mathrm{O}_{3}\right)$ which includes a scaling break, must have a change in functional form which is more than a local maximum or change in curvature and is related to change in the temporal dynamics controlling ozone production. However, the similarity function developed by Ainslie and Steyn 15 (2005) shows the scaling break arising from a plot of (Weibull transformed and dimensionless) $\left[\mathrm{O}_{3}\right]_{\max } /\left[\mathrm{NO}_{\mathrm{x}}\right]_{0}$ versus $R$. To understand the link between the two, we note the present analysis shows the relative abundance of VOC to $\mathrm{NO}_{\mathrm{x}}(R$-value) determines whether the switch in chemical regimes occurs within the given process time (c.f. Property IV). Thus precursor mixtures with $R$-values greater than $\beta$ will switch to the low production regime during the process time; noticeably limiting maximum ozone concentrations (the plotting of maximum ozone concentration divided by initial $\mathrm{NO}_{\mathrm{x}}$ concentration serves to scale the model output onto a single curve and does not contribute to the break in scaling). Thus the behaviour of the $\left[\mathrm{O}_{3}\right]_{\max } /\left[\mathrm{NO}_{\mathrm{x}}\right]_{0}$ versus $R$ curve will change for $R$-values greater than $\beta$.

25 Property VI suggests it should be possible to extend the parameterization of the similarity relationship (Eq. 10 of Ainslie and Steyn, 2005) to include a temporal dependence
ACPD

$5,12985-13010,2005$

\section{Scaling ozone photochemistry II}

B. Ainslie and D. G. Steyn

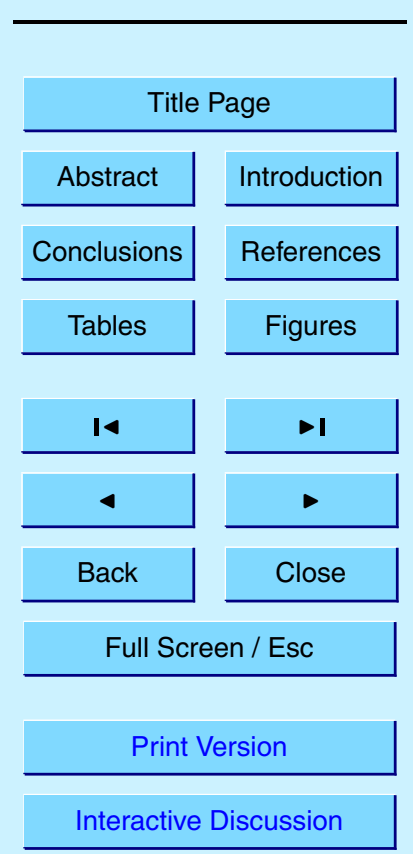

EGU 
through the replacement of $R$ with $R j^{C}$ :

$\frac{\left[\mathrm{O}_{3}\right]}{j_{a v} / k_{\mathrm{NO}}}\left(j(t), R,\left[\mathrm{NO}_{\mathrm{x}}\right]_{\mathrm{O}}\right)=\gamma\left(\frac{\left[\mathrm{NO}_{\mathrm{x}}\right]_{\mathrm{O}}}{j_{a v} / k_{\mathrm{NO}}}\right)^{a}\left(1-\exp \left[-\lambda\left(\frac{R}{\beta}\left(\frac{j}{J}\right)^{c}\right)^{\alpha}\right]\right)$

where $j\left(t_{\text {end }}\right)=J$. To see how well this parameterization holds, it has been compared with model output from the RADM2 mechanism using a urban VOC (Stockwell et al., 5 1997) in Fig. 5. Parameter values for Eq. (4) were not found by regression against the temporal ozone profiles but against 100 maximum ozone and initial $\mathrm{VOC}$ and $\mathrm{NO}_{\mathrm{x}}$ triplets as described in Ainslie and Steyn (2005). Except for the low $R /$ low $\mathrm{NO}_{\mathrm{x}}$ plots $\left(R=6\right.$ and $\left.\left[\mathrm{NO}_{\mathrm{x}}\right]_{0}=0.015,0.045 \mathrm{ppm}\right)$, Eq. (4) shows good agreement with the model output. In many cases, Eq. (4) does not match the transition time exactly but does 10 manage to be within $\pm 10 \%$. In the next section, we use scaling behaviour properties, developed from model output, to analyze smog chamber data.

\section{Scaling properties of smog chamber data}

Smog chamber data from a series of experiments performed at the CSIRO outdoor smog chamber facility in the North Ryde suburb of Sydney (latitude $33^{\circ} 52^{\prime} \mathrm{S}$, longitude $151^{\circ} 13^{\prime} \mathrm{E}$ ) was used in the analysis. The data consist of ten sets of experiments performed in two separate cubical smog chambers using a mixture of VOCs typical of Sydney's air (Hess et al., 1992). All experiments were performed without dilution and with the VOC and $\mathrm{NO}_{x}$ initially well mixed. Typically, the experiments started at sunrise and continued until late afternoon. Table 1 lists the test conditions for the 20 experiments. As Table 1 shows, the CSIRO data set covers only a limited range of $R$-values $([1.6,10.2])$, so temporal ozone concentrations (as a function of $R j^{c}$ ) were examined (using Eq. 4) to allow an analysis over a wider range. To complicate matters, the experiments span a wide range of temperatures which must be accounted for.

We start by expressing the data as dimensionless groups: $\pi\left(=\left[\mathrm{O}_{3}\right] /\left(k_{\mathrm{NO}} / j_{a v}\right)\right)$ 25 for the ozone concentrations, $\pi_{1}\left(=\left[\mathrm{NO}_{\mathrm{x}}\right]_{0} /\left(k_{\mathrm{NO}} / j_{\mathrm{av}}\right)\right)$ for the initial $\mathrm{NO}_{\mathrm{x}}$ concen12995

\section{Scaling ozone photochemistry II}

B. Ainslie and D. G. Steyn

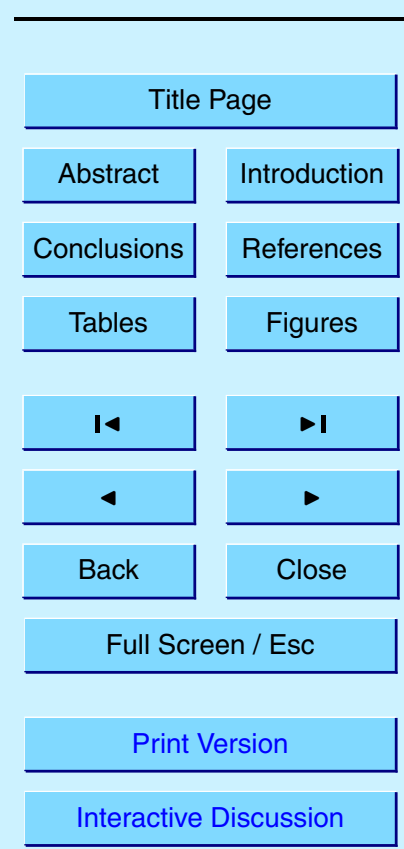

EGU 
trations, $\pi_{2}\left(=[\mathrm{VOC}]_{0} /\left[\mathrm{NO}_{\mathrm{x}}\right]_{0}\right)$ for the relative abundance of $\mathrm{VOC}$ to $\mathrm{NO}_{\mathrm{x}}$ and $\pi_{4}=\exp [-504(1 /(\operatorname{Tav}+273)-1 / 298)]$ for the dimensionless temperature dependence $^{3}$. In terms of Pi-groups the scaling analysis suggests:

$$
\frac{\pi}{\pi_{1}^{a} \pi_{4}^{b}}=\gamma f\left(\pi_{2} j^{c}\right)
$$

5 and so the objective is to plot $\pi /\left(\pi_{1}^{a} \pi_{4}^{b}\right)$ versus $\pi_{2} j^{c}$ to determine if the data collapse onto a common curve and to see if this curve (i.e. the similarity relationship) can be parameterized by a composite of two Weibull functions. To test these two conjectures, the following steps were taken:

1. For each experiment, the total $\mathrm{NO}_{2}$ photolysis rate and total test time were used to calculate the average photolysis rate $\left(j_{a v}\right)$.

2. The average temperature was used to determine $k_{\mathrm{NO}}$ and $\pi_{4}$.

3. The initial $\mathrm{NO}_{\mathrm{x}}$ concentration was used to determine $\pi_{1}$; the initial $\mathrm{VOC}$ and $\mathrm{NO}_{\mathrm{x}}$ concentrations for $\pi_{2}$; and ozone concentrations for $\pi$

4. The cumulative $\mathrm{NO}_{2}$ photolysis rate was used to determine $j(t)$ based on calculated local solar elevation.

The resulting dimensionless data are plotted as a function of $\pi_{2} j^{c}$ in Fig. 6A. Also shown on this plot is the similarity function $f\left(\pi_{2} j(t)^{c}\right)$ that best fits the data. Values for the three exponents $(a, b, c)$ as well as the similarity parameters are given in Table 2. The level of agreement between the similarity function and the data can be seen in the scatter plot of observed versus calculated ozone concentrations (Fig. 6B). The plot shows our model fitting the data quite well (the scatter plot statistics are given in Table 3) with little bias.

\footnotetext{
${ }^{3}$ We have slightly modified our dimensionless temperature with the inclusion of the $\exp [504 / 298]^{b}$ term to be consistent with IER model (Johnson, 1984).
}

12996

\section{ACPD}

5, 12985-13010, 2005

\section{Scaling ozone photochemistry II}

B. Ainslie and D. G. Steyn

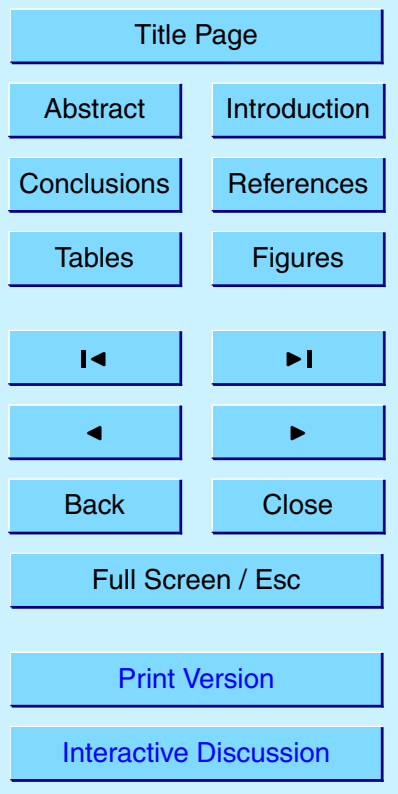

EGU 
The dimensionless data, after normalization and Weibull transformation are plotted in Fig. 6C. It is difficult to see the scaling break in Fig. $6 \mathrm{C}$ because the "kink" in the data $\left(\right.$ at $\left.\ln \left(R j^{c}\right)=9.7\left(R j^{c}=17000\right)\right)$ is slight. While the data support the break, it is not as distinct as those seen in the model output for the reactive RADM2 classes (Ainslie and

5 Steyn, 2005). For a sharp break to occur, a large change in ozone production is needed across $R=\beta$. We suspect this change can be understood in terms of the strength of $\mathrm{NO}_{\mathrm{x}}$-inhibition occurring within a VOC-NO mixture. At low $\mathrm{VOC}$ to $\mathrm{NO}_{\mathrm{x}}$ ratios, ozone formation is constrained by radical availability with $\mathrm{NO}_{2}$ and VOCs in competition from the mainly ozone-produced $\mathrm{OH}^{\bullet}$ radicals. Under these conditions, increasing $\mathrm{NO}_{\mathrm{x}}$ con10 centrations increases competition for $\mathrm{OH}^{\bullet}$ and ozone formation slows, further limiting radical availability. We find VOC classes which readily produce their own photolytic source of radicals (e.g. $\mathrm{HCHO}$ ), and hence are less affected by $\mathrm{NO}_{\mathrm{x}}$-inhibition, have less pronounced scaling breaks (Ainslie, 2004). Since smog chambers are often plagued by unaccounted radical sources (Carter et al., 1981), it is possible that such 15 sources reduce the $\mathrm{NO}_{\mathrm{x}}$-inhibition of the smog chamber mixtures; in fact Tonnesen and Jeffries (1994) show the GRS mechanism, developed from CSIRO smog chamber data, shows noticeably less $\mathrm{NO}_{\mathrm{x}}$-inhibition than the $\mathrm{CB} 4$ chemical mechanism.

\section{Conclusions}

In this paper we have explored the similarity relationship using semi-quantitative mod20 els and model output. Our analysis shows the scaling break arises from a change in the temporal evolution of ozone production. Our analysis suggests the initial relative abundance of VOC to $\mathrm{NO}_{\mathrm{x}}$ ( $R$-value) determines whether the switch in processes will occur within a fixed process time. The $R$-value at the break $(\beta)$ can be used to create a process-based ridgeline on an isopleth diagram that lies above a sensitivity based $25\left(\mathrm{~d}\left[\mathrm{O}_{3}\right]_{\max } / \mathrm{d}\left[\mathrm{NO}_{\mathrm{x}}\right]_{0}=0\right)$ ridgeline. As Sillman (1999) points out, the actual split between VOC and $\mathrm{NO}_{\mathrm{x}}$-sensitive is better viewed as a broad transition region rather than a sharp line. For this reason, we propose the most natural division of an ozone response
ACPD

5, 12985-13010, 2005

\section{Scaling ozone photochemistry II}

B. Ainslie and D. G. Steyn

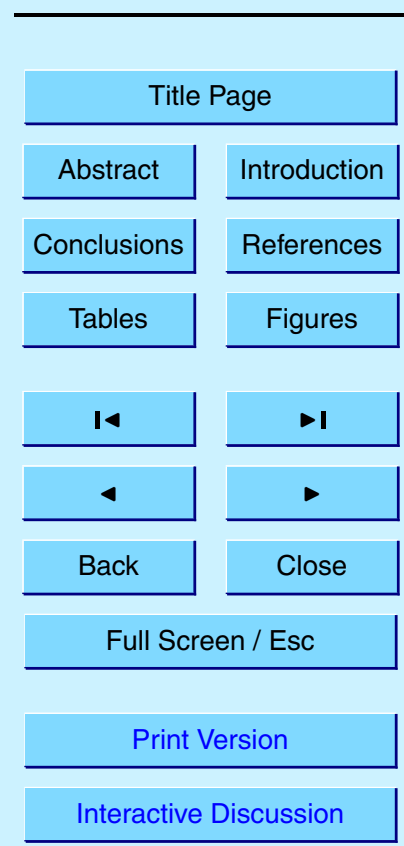

EGU 
surface is into three regions: $\mathrm{VOC}$ sensitive (or $\mathrm{NO}_{x}$-saturated) region, ridge or transition region and a region where maximum ozone concentrations scale with initial $\mathrm{NO}_{\mathrm{x}}$ concentrations only ( $\mathrm{NO}_{\mathrm{x}}$-only scaling region). We suggest $\beta$ marks the boundaries between the VOC-sensitive/ridge regions.

5 Our analysis has allowed us to developed a set of properties that characterize ozoneprecursor relationships. These findings, all based on model output, generalizes the IER model, developed from smog chamber data. These properties have also enabled us to include a temporal dependence into the similarity parameterization of Ainslie and Steyn (2005) (Eq. 9) which can be used to quantitatively describe ozone formation.

10 The scaling methods were applied to smog chamber data allowing observations from a variety of experiments, having different initial precursor concentrations, temperatures and actinic fluxes, to be presented on a common graph. Only a slight break in the corresponding Weibull transformed observations was seen with the chamber data. The present analysis cannot tell if the lack of sharp break is due to experimental uncertainties stemming from the presence of the chamber membrane (especially if these act as additional radical sources); a bias in the test conditions with more experiments performed at $R$-values below the scaling break; or if chemical mechanisms overly enhance the process leading to the scaling break. More research is needed in this area, perhaps making use of ambient ozone concentrations drawn from a variety of environments.

\section{Appendix}

The IER model consists of a simple set of formulae which quantitatively describe ozone formation developed from the analysis of an extensive set of outdoor smog chamber experiments (Johnson, 1984). The model predicts that initially, smog potential (PSP) $\left(\left[\mathrm{O}_{3}\right](\mathrm{t})-\left[\mathrm{O}_{3}\right](0)-[\mathrm{NO}](0)+[\mathrm{NO}](\mathrm{t})\right)$ increases linearly with $j(t)$ and initial VOC concentra-
ACPD

5, 12985-13010, 2005

\section{Scaling ozone photochemistry II}

B. Ainslie and D. G. Steyn

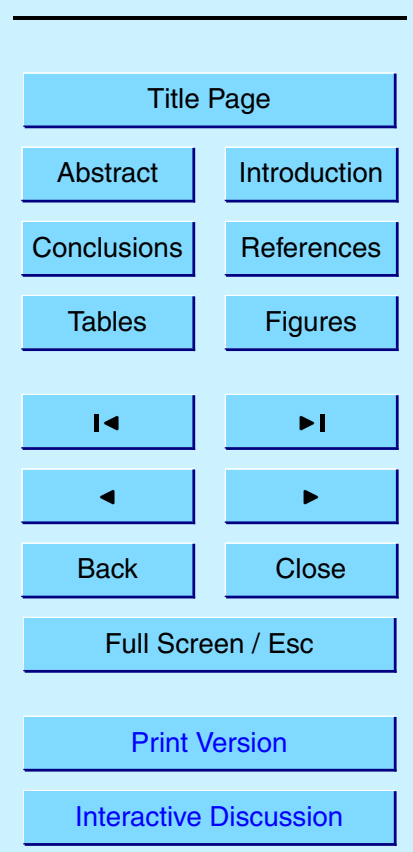

EGU 
tion until reaching a constant value:

$P S P= \begin{cases}k f(T)[\mathrm{VOC}]_{\mathrm{O}} j(t), & k f(T)[\mathrm{VOC}]_{\mathrm{O}} j(t)<\beta\left[\mathrm{NO}_{\mathrm{x}}\right]_{\mathrm{O}} \\ \beta\left[\mathrm{NO}_{\mathrm{x}}\right]_{0}, & k f(T)[\mathrm{VOC}]_{\mathrm{O}} j(t) \geq \beta\left[\mathrm{NO}_{\mathrm{x}}\right]_{\mathrm{O}}\end{cases}$

5, 12985-13010, 2005

where $k$ is a constant and $f(T)$ is a temperature dependent measure of VOC reactivity. The corresponding parameterization for $P S P$ production $(P(P S P))$ has:

$P_{j}(P S P)= \begin{cases}k f(T)[\mathrm{VOC}]_{0}, & k f(T)[\mathrm{VOC}]_{0} j(t)<\beta\left[\mathrm{NO}_{\mathrm{x}}\right]_{0} \\ 0, & k f(T)[\mathrm{VOC}]_{0} j(t) \geq \beta\left[\mathrm{NO}_{\mathrm{x}}\right]_{0}\end{cases}$

From Eqs. (A1) and (A2) we find:

- $P_{j}(P S P)$ increases with $[\mathrm{VOC}]_{0}=R\left[\mathrm{NO}_{\mathrm{x}}\right]_{0}$ (Property II)

- the parameterization for $P\left(P S P_{j}\right)$ shows a discontinuity when $k f(T)[\mathrm{VOC}]_{0}=\beta\left[\mathrm{NO}_{\mathrm{x}}\right]_{\mathrm{o}}$ (Property III).

Scaling ozone photochemistry II

B. Ainslie and D. G. Steyn

- The transition time $\left(j^{*}\right)$ occurs when:

$j(t)=\frac{\beta}{k f(T)} \frac{\left[\mathrm{NO}_{\mathrm{x}}\right]_{\mathrm{O}}}{[\mathrm{VOC}]_{\mathrm{O}}} \propto \frac{1}{R}$

i.e. transition occurs sooner for larger $R$-values (Property IV).

- $\int_{0}^{j^{*}} P j(P S P) d j=\int_{0}^{j>j^{*}} P_{j}(P S P) d j=\beta\left[\mathrm{NO}_{\mathrm{x}}\right]_{0}$

showing the area under the production curve at the transition, as well as the total area are functions of initial $\mathrm{NO}_{\mathrm{x}}$ concentration (Property $\mathrm{V}$ ).

- The parameterization for $[P S P]$ is a function of $[\mathrm{VOC}]_{0} j(t)=\left[\mathrm{NO}_{\mathrm{x}}\right]_{0} R j(t)$ which scales with $R \times j^{c}(t)$ with $c=1$ (Property $\mathrm{VI}$ ).

Thus we can think of the IER model as a parameterization of $P S P$ production, using a step function, which satisfies Properties II-V.

Title Page

Abstract

Introduction

Conclusions

Tables

References

Figures

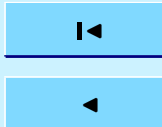

Back

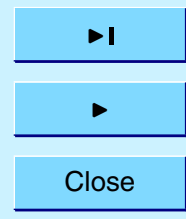

Full Screen / Esc

Print Version

Interactive Discussion

EGU 
Acknowledgements. Funding for this research was through the University of British Columbia graduate fellowships (UGF), the National Science and Engineering Research Council (NSERC) and the Canadian Foundation for Climate and Atmospheric Sciences (CFCAS).

\section{References}

5 Ainslie, B. and Steyn, D. G.: A Scaling Analysis of Ozone Photochemistry: I Model Development, Atmos. Chem. Phys. Discuss., 5, 12957-12983, 2005,

SRef-ID: 1680-7375/acpd/2005-5-12957. 12987, 12989, 12990, 12992, 12993, 12994, 12995, 12997, 12998

Ainslie, B. D.: A Photochemical Model Based on a Scaling Analysis of Ozone Photochemistry,

$10 \quad$ PhD thesis, University of British Columbia, Vancouver, B.C., Canada, 311 pp., 2004. 12997

Blanchard, C. L.: Ozone process insights from field experiments - Part III: Extent of reaction and ozone formation, Atmos. Environ., 34, 2035-2043, 2000. 12990, 12994

Blanchard, C. L., Lurman, F. W., Korc, M., and Roth, R. M.: The use of ambient data to corroborate analyses of ozone control strategies, Tech. Rep. STI-94030-1433-FR, Sonoma Technology Inc., 1994. 12990

Blanchard, C. L., Lurman, F. W., Roth, P. M., Jeffries, H. E., and Roth, R. M.: An introduction to the Generic Reaction Set, Atmos. Environ., 33, 369-381, 1999. 12986

Carter, W. P. L., Atkinson, R., Winer, A. M., and Pitts Jr., J. N.: Evidence for ChamberDependent Radical Sources, Int. J. Chem. Kinet., 13, 735-740, 1981. 12997

Chang, T. Y. and Rudy, S. J.: Ozone-precursor relationships: a modeling study of semiempirical relationships, Environ. Sci. Technol., 27, 2213-2219, 1993. 12994

Hess, G. D., Carnovale, F., Cope, M. E., and Johnson, G. M.: The Evaluation of some photochemical smog reaction mechanisms - I. Temperature and initial composition effects, Atmos. Environ., 26A, 625-641, 1992. 12995, 13002

Johnson, G. M.: A simple model for predicting ozone concentration of ambient air, in: Proceedings of the Eighth International Clean Air Conference, pp. 716-731, Melbourne Australia, 1984. 12987, 12988, 12990, 12996, 12998

Kirchner, F., Jeanneret, F., Clappier, A., Krüger, B., van den Bergh, H., and Calpini, B.: Total VOC reactivity in the planetary boundary layer 2 . A new indicator for determining the sensi-

\section{Scaling ozone photochemistry II}

B. Ainslie and D. G. Steyn

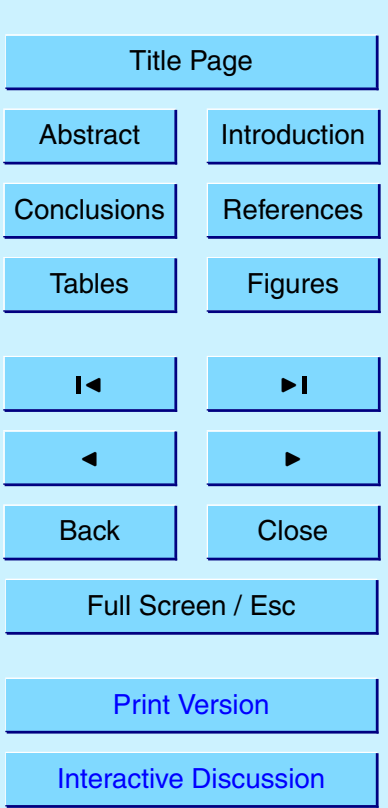

EGU 
tivity of the ozone production to VOC and NOx, J. Geophys. Res., 106, 3095-3110, 2001. 12986

Kleinman, L. I.: Low and High NOx tropospheric photochemistry, J. Geophys. Res., 99, $16831-$ 16838, 1994. 12991

5 Kleinman, L. I.: The dependence of tropospheric ozone production rate on ozone precursors, Atmos. Environ., 39, 575-586, 2005. 12986

National Research Council: Rethinking the Ozone Problem in Urban and Regional Air Pollution, National Academy Press, Washington, D.C., 500 pp., 1991. 12986

Sillman, S.: The use of $\mathrm{NO}_{\mathrm{y}}, \mathrm{H}_{2} \mathrm{O}_{2}$ and $\mathrm{HNO}_{3}$ as indicators for ozone-NOx-hydrocarbon sensitivity in urban locations, J. Geophys. Res., 100, 14 175-14 188, 1995. 12986

Sillman, S.: The relationship between ozone, NOx and hydrocarbons in urban and polluted rural environments, Atmos. Environ., 33, 1821-1845, 1999. 12997

Stockwell, W. R., Middleton, Chang, J., and Tang, X.: The second generation regional acid deposition model chemical mechanism for regional air quality modeling, J. Geophys. Res.,

15 95, 16343-16 367, 1990. 13009

Stockwell, W. R., Kirchner, F., and Kuhn, M.: A new mechanism for regional atmospheric chemistry modeling, J. Geophys. Res., 102, 25 847-25 879, 1997. 12992, 12995

Tonnesen, G. S. and Dennis, R. L.: Analysis of radical propagation efficiency to assess ozone sensitivity to hydrocarbons and NOx 1. Local indicators of instantaneous odd oxygen production sensitivity, J. Geophys. Res., 105, 9213-9225, 2000. 12986

Tonnesen, S. and Jeffries, H. E.: Inhibition of odd oxygen production in the Carbon Four and Generic Reaction Set mechanism, Atmos. Environ., 28, 1339-1349, 1994. 12990, 12997

\section{ACPD}

$5,12985-13010,2005$

\section{Scaling ozone photochemistry II}

B. Ainslie and D. G. Steyn

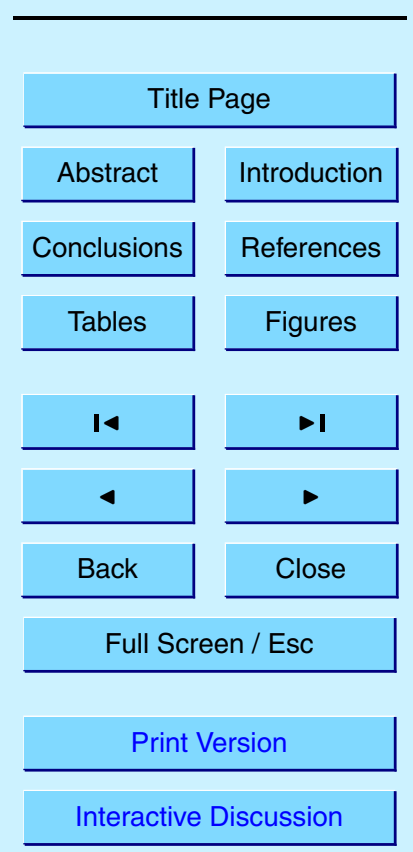




\section{ACPD}

Table 1. Test conditions for the $10 \mathrm{CSIRO}$ smog chamber experiments. The VOC is a mixture of organics typically found in the Sydney air (Hess et al., 1992). The total $\mathrm{NO}_{2}$ photolysis rate is given by $J$ while $j_{a v}$ is its average value over the duration of the experiment.

\begin{tabular}{ccccccccc}
\hline Test name & Month & Date & {$[\mathrm{VOC}]_{0}(\mathrm{ppb})$} & {$\left[\mathrm{NO}_{\mathrm{x}}\right]_{0}(\mathrm{ppb})$} & $\mathrm{R}$ & $T_{a v}(\mathrm{C})$ & $\mathrm{J}$ & $j_{a v}\left(\mathrm{~s}^{-1}\right)$ \\
\hline 340P & September & 21 & 200.0 & 19.6 & 10.2 & 22.5 & 228.3 & 0.00634 \\
340L & September & 21 & 200.0 & 19.7 & 10.2 & 22.2 & 227.6 & 0.00632 \\
341P & September & 28 & 200.0 & 53.4 & 3.7 & 18.0 & 231.2 & 0.00642 \\
341L & September & 28 & 200.0 & 24.8 & 8.1 & 17.4 & 226.9 & 0.00664 \\
342P & October & 5 & 100.0 & 54.0 & 1.9 & 22.2 & 248.4 & 0.00657 \\
342L & October & 5 & 200.0 & 55.6 & 3.6 & 21.2 & 250.5 & 0.00633 \\
343P & October & 10 & 400.0 & 53.6 & 7.5 & 21.5 & 250.8 & 0.00664 \\
343L & October & 10 & 100.0 & 54.5 & 1.8 & 21.5 & 247.3 & 0.00654 \\
344P & October & 11 & 200.0 & 44.6 & 4.5 & 26.9 & 251.3 & 0.00665 \\
344L & October & 11 & 400.0 & 46.2 & 8.7 & 26.0 & 253.9 & 0.00672 \\
345P & October & 19 & 200.0 & 100.4 & 2.0 & 28.5 & 250.8 & 0.00697 \\
345L & October & 19 & 400.0 & 97.2 & 4.1 & 28.8 & 245.0 & 0.00717 \\
359P & March & 15 & 100.0 & 30.9 & 3.2 & 25.2 & 174.6 & 0.00809 \\
359L & March & 15 & 50.0 & 28.2 & 1.8 & 25.0 & 187.1 & 0.00800 \\
360P & March & 19 & 50.0 & 31.4 & 1.6 & 22.8 & 215.2 & 0.00664 \\
360L & March & 19 & 100.0 & 30.3 & 3.3 & 22.7 & 221.6 & 0.00648 \\
361P & March & 21 & 100.0 & 17.4 & 5.7 & 22.4 & 225.0 & 0.00622 \\
361L & March & 21 & 100.0 & 31.1 & 3.2 & 22.5 & 230.9 & 0.00639 \\
362P & March & 26 & 50.0 & 19.3 & 2.6 & 25.2 & 241.9 & 0.00640 \\
362L & March & 26 & 100.0 & 18.9 & 5.3 & 24.7 & 237.9 & 0.00630 \\
\hline
\end{tabular}

5, 12985-13010, 2005

\section{Scaling ozone photochemistry II}

B. Ainslie and D. G. Steyn

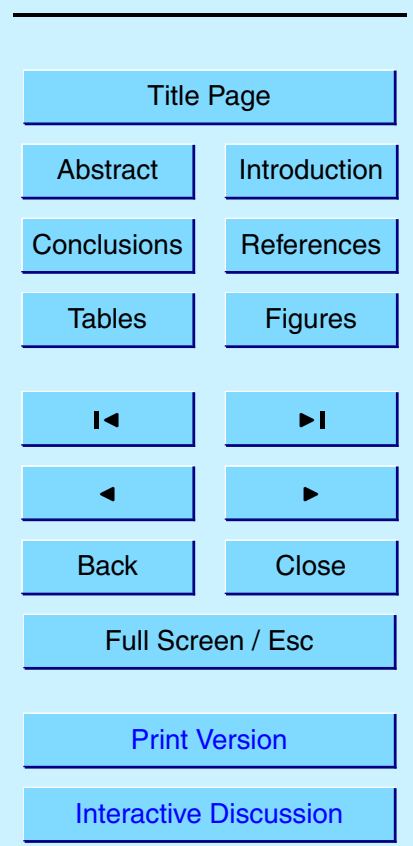

EGU 


\section{ACPD}

5, 12985-13010, 2005

Scaling ozone photochemistry II

B. Ainslie and D. G. Steyn

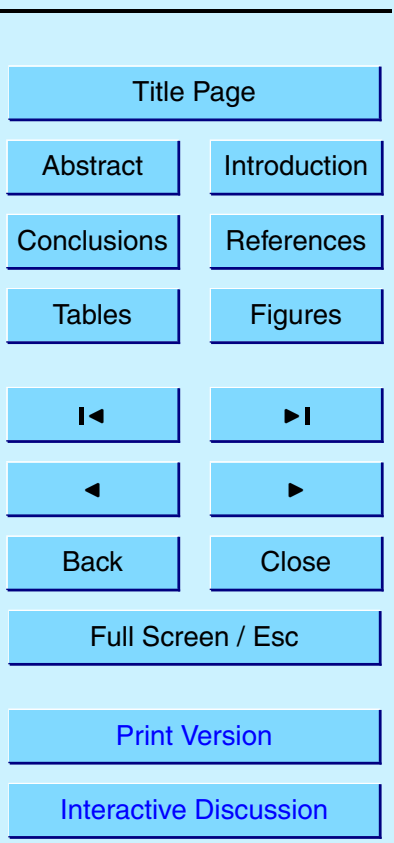

EGU 


\section{ACPD}

5, 12985-13010, 2005

Scaling ozone photochemistry II

B. Ainslie and D. G. Steyn

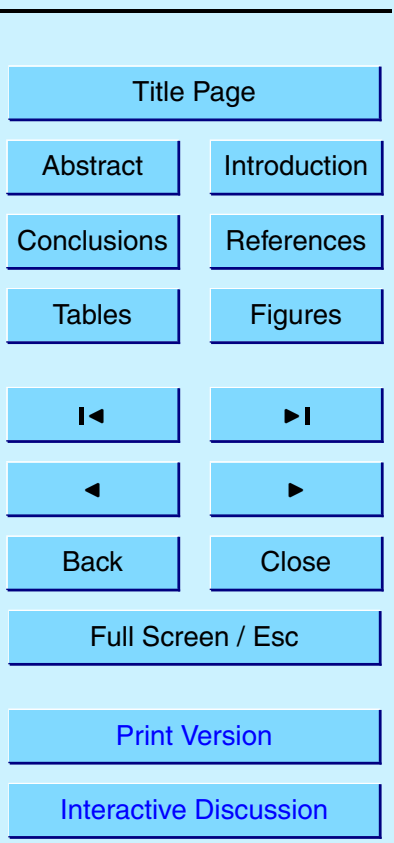

EGU 


\section{ACPD}

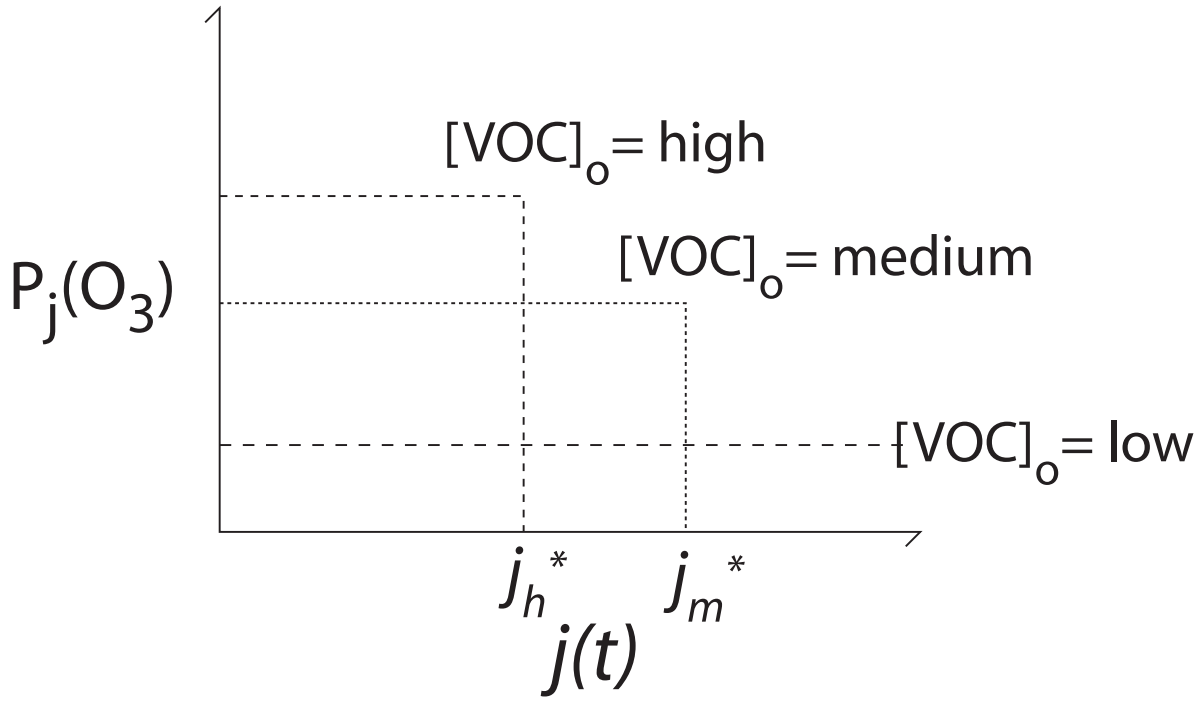

Fig. 1. Three members of a family of a step-function model for ozone production. The high $[\mathrm{VOC}]_{0}$ switches to zero production at $j_{h}^{*}$, the medium at $j_{m}^{*}$ while the low VOC never switches in the examined process time.
$5,12985-13010,2005$

Scaling ozone photochemistry II

B. Ainslie and D. G. Steyn

Title Page

\begin{tabular}{c|c} 
Abstract & Introduction \\
Conclusions & References \\
\cline { 2 - 3 } Tables & Figures \\
\hline
\end{tabular}

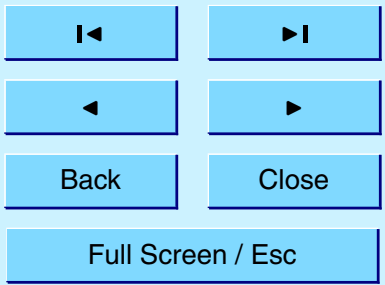

Print Version

Interactive Discussion 

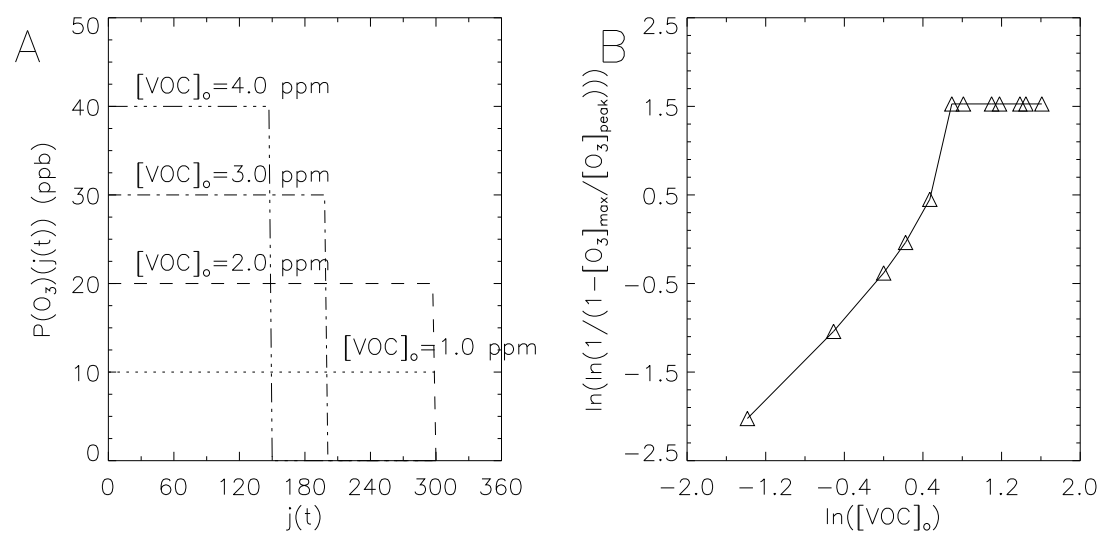

\section{ACPD}

$5,12985-13010,2005$

\section{Scaling ozone photochemistry II}

B. Ainslie and D. G. Steyn
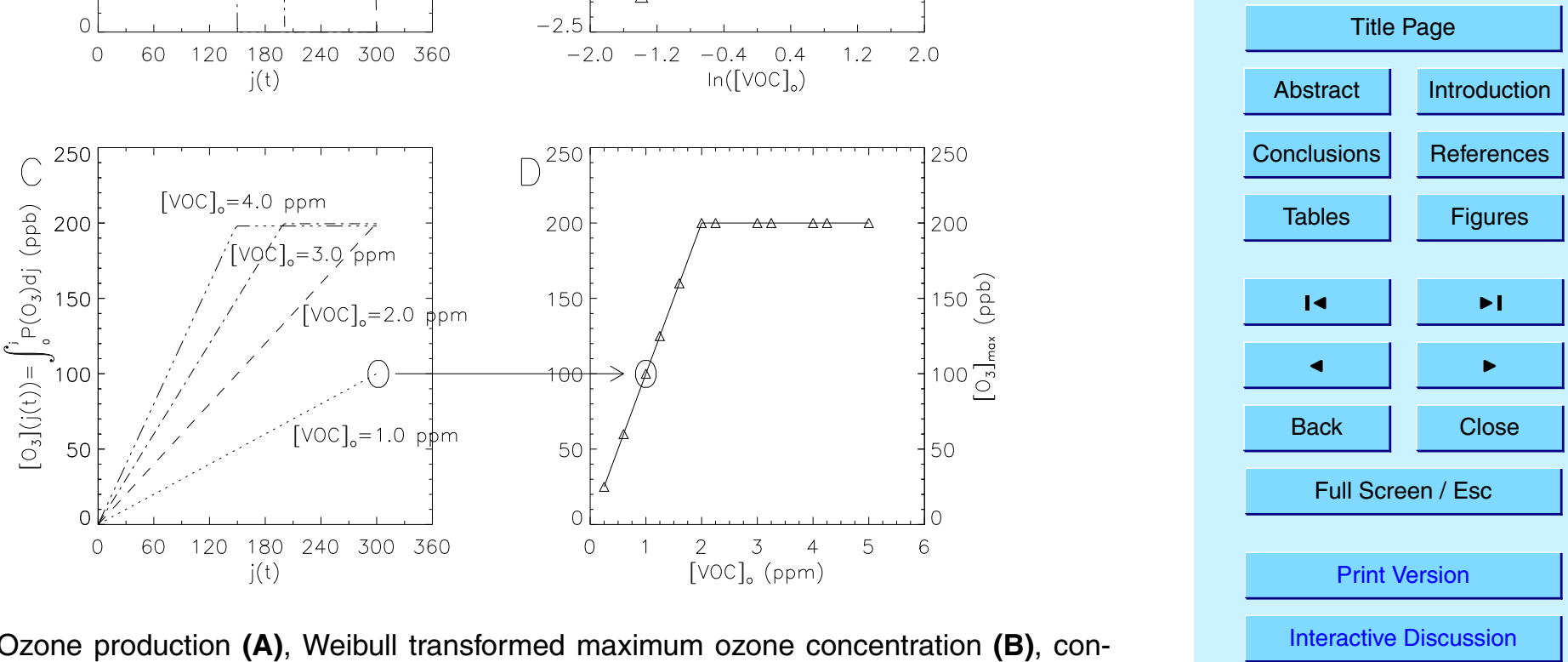

Fig. 2. Ozone production (A), Weibull transformed maximum ozone concentration (B), conInteractive Discussion centration (C) and maximum concentration (D) for a step function model. The arrow between Figs. (C) and (D) highlights the relationship between final ozone concentration and maximum ozone concentration.

EGU 


\section{ACPD}

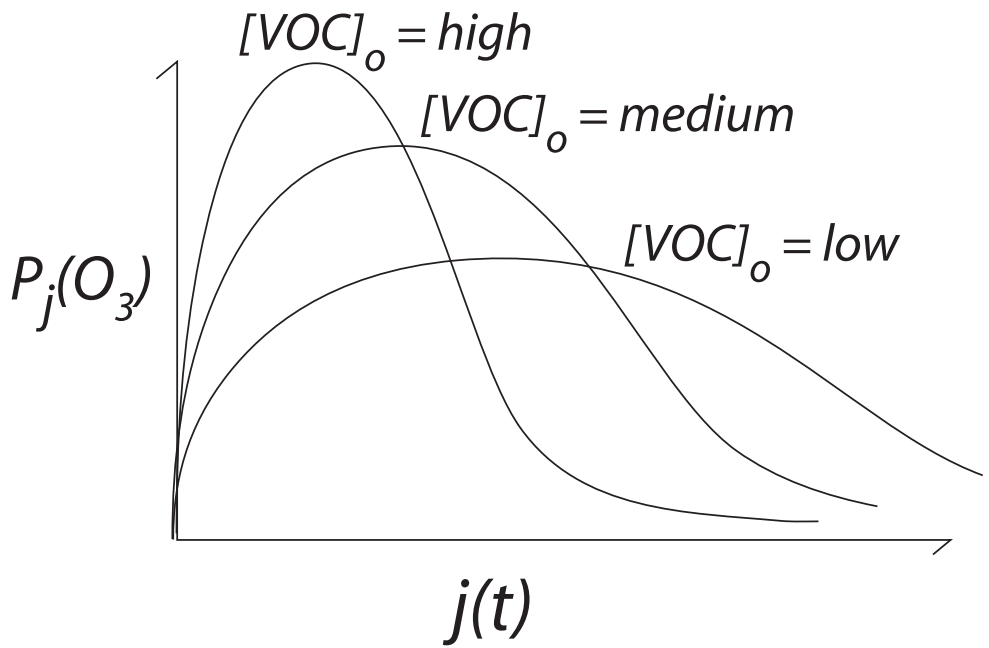

Fig. 3. Three members of a family of a model for ozone production which increases, reaches a peak value and decays.
$5,12985-13010,2005$

Scaling ozone photochemistry II

B. Ainslie and D. G. Steyn

Title Page

\begin{tabular}{c|c} 
Abstract & Introduction \\
\cline { 1 - 1 } Conclusions & References \\
\cline { 1 - 2 } Tables & Figures \\
\cline { 2 - 3 }
\end{tabular}

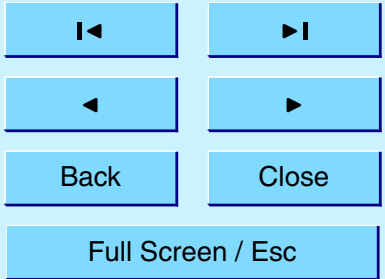

Print Version

Interactive Discussion 


\section{ACPD}

$5,12985-13010,2005$
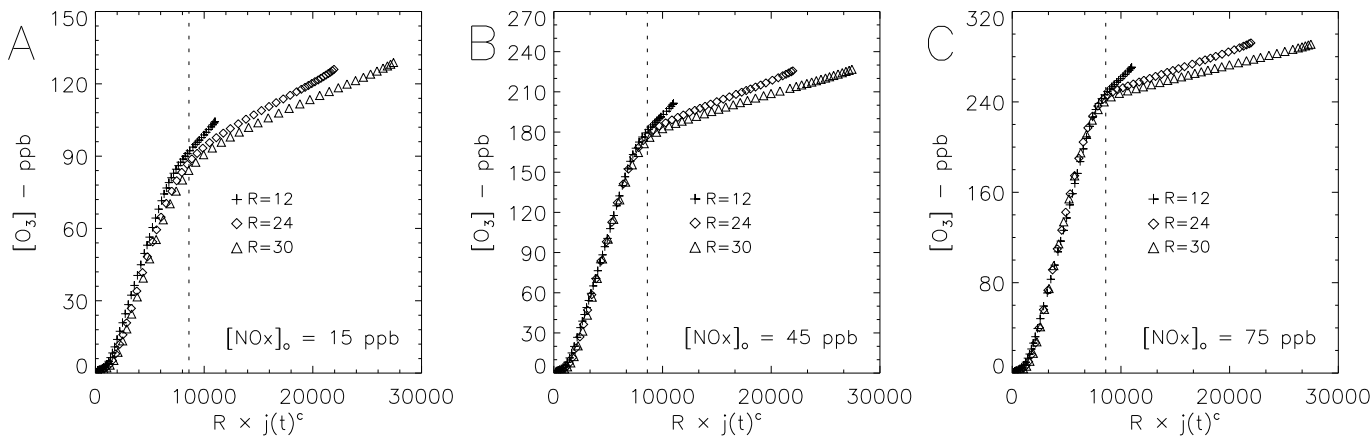

\section{Scaling ozone photochemistry II}

B. Ainslie and D. G. Steyn

Fig. 4. Ozone concentration as a function of $R \times j(t)^{c}(c=1.2)$ for nine different initial $\mathrm{NO}_{\mathrm{x}}$ and VOC conditions. In Fig. (A), all simulations started with $15 \mathrm{ppb} \mathrm{NO}$ and with $45 \mathrm{ppb}$ in (B) and $75 \mathrm{ppb}$ in (C). In each figure initial VOC concentrations are chosen so that the resulting $R$-values are: $12,24,30$. Also shown in each plot is a vertical line at $R \times j(t)^{C}=8600$.

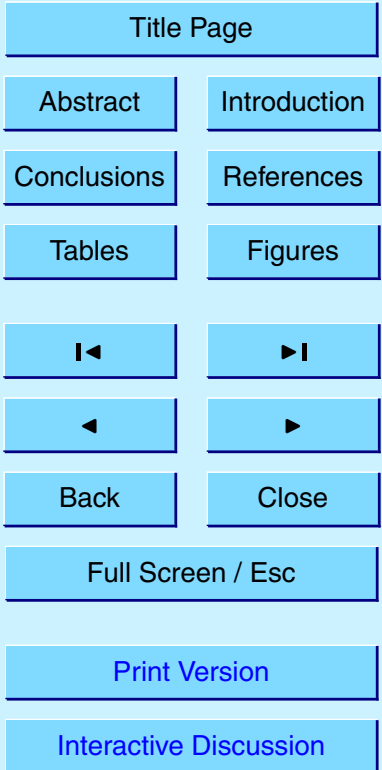

EGU 

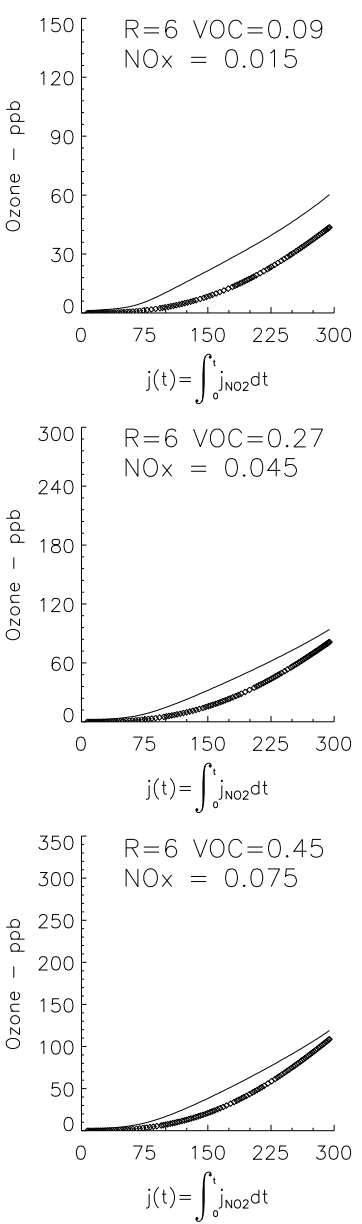
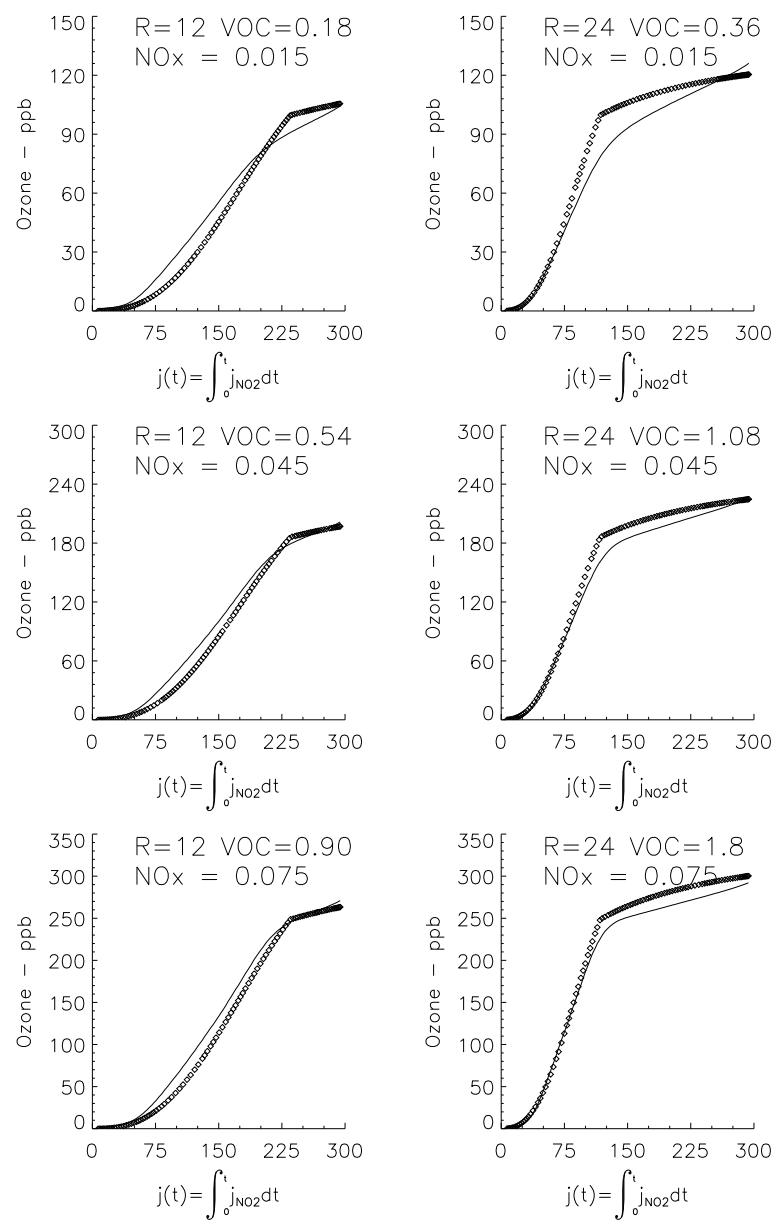

ACPD

5, 12985-13010, 2005

Scaling ozone photochemistry II

B. Ainslie and D. G. Steyn
Title Page

Abstract Introduction

Conclusions

References

Tables

Figures

Print Version

Interactive Discussion

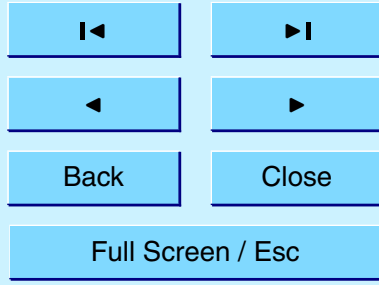

Fig. 5. Ozone concentration versus time for a series of nine box model simulations. Solid EGU lines represent model output using the RADM2 mechanism (Stockwell et al., 1990) and circles represent results based on Eq. (4). 

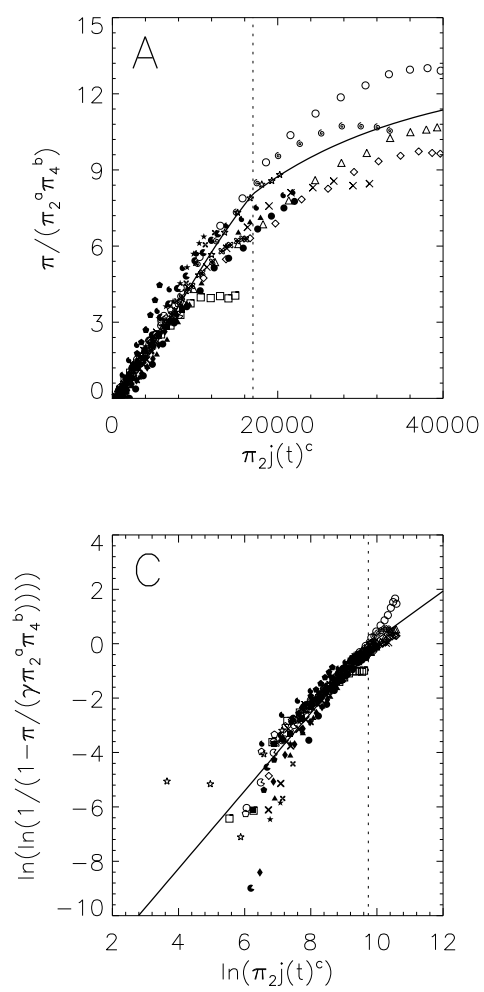

Fig. 6. Comparison of the similarity function and the CSIRO smog chamber data. Figure (A) shows the non-dimensional data as a function of $R j(t)^{C}$. Also shown (solid line) is the similarity function which best fits the data and the location of the scaling break (dotted line). The model has been used to calculated ozone concentrations which are compared with the actual concentrations is Fig. (B). Figure (C) shows the data in the Weibull plane along with the similarity function (solid line) and the scaling break (dotted line).

\section{ACPD}

5, 12985-13010, 2005

\section{Scaling ozone photochemistry II}

B. Ainslie and D. G. Steyn

50100150200250300

$\left[\mathrm{O}_{3}\right](\mathrm{ppb})$ Calculated

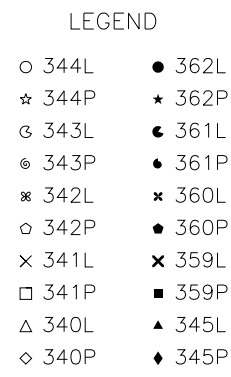

Abstract

Title Page

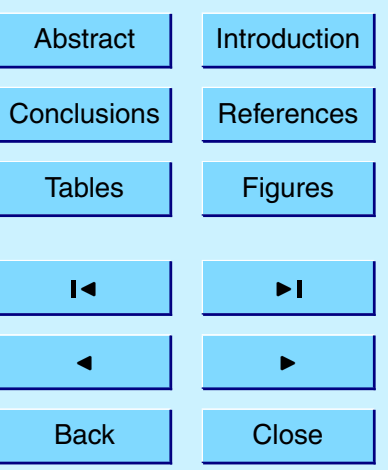

Full Screen / Esc

Print Version

Interactive Discussion 